\title{
MEV como ferramenta na determinação de sais formados em uma lagoa salina no Pantanal. Estudo de Caso
}

\author{
Mario Rubens Gomes Santos * \\ Joel Barbujiani Sígolo \\ Universidade de São Paulo \\ Instituto de Geociências da USP. \\ Departamento de Geologia Sedimentar e \\ Ambiental \\ Rua do Lago 562, \\ Cidade Universitária \\ Sao Paulo, SP - Brasil \\ CEP 05422-970 \\ * Autor Correspondente: \\ mario.santos@usp.br
}

\begin{abstract}
RESUMO
O presente trabalho consiste do estudo de sais formados "in situ" em uma lagoa salina, localizada no Pantanal, na sub-região da Nhecolândia. O objetivo foi caracterizar os sais coletados nas bordas de uma salina, fornecendo dados que auxiliem no entendimento a respeito do ambiente químico/geoquímico de formação desses sais. $\mathrm{O}$ ambiente de formação dos sais é caracterizado pelo elevado $\mathrm{pH}(<9)$ e pela alta salinidade $\left(40.000 \mu \mathrm{S} . \mathrm{cm}^{-1}\right)$, condições que favorecem a precipitação e desenvolvimento dos sais. Os sais foram estudados quanto a sua morfologia e composição química. As morfologias mais frequentes são os hábitos lamelar, fibroso e formato alongado. Quanto à composição química se destaca como predominante a trona $\left(\mathrm{Na}_{3} \mathrm{H}\left(\mathrm{CO}_{3}\right)_{2} .2 \mathrm{H} 2 \mathrm{O}\right)$. Em relação ao seu modo de ocorrência, os sais ocorrem aglomerados, os cristais se apresentam aglutinados, formados sobre e ao redor dos grãos de quartzo, utilizando sua estrutura como zona de nucleação.
\end{abstract}

Palavras-Chave: SEM/ Xray-EDS; Lagos, sais, Pantanal

\section{ABSTRACT}

The present work is based on the study of saline lagoon salts formed in a salt lake located in the Nhecolândia, a sub-region of Pantanal. The objective was to characterize the salts collected at the edge of a saline, providing data to support the understanding the chemistry/geochemistry of the salt formation in the environment. This environment is characterized by high $\mathrm{pH}(<9)$ and high salinity $\left(40,000 \mu \mathrm{S} . \mathrm{cm}^{-1}\right)$, conditions that favor the precipitation and salt development. The salts were studied about their morphology and chemical composition. The most frequent morphologies are lamellar, fibrous habits and elongated forms. As for the chemical composition, these are salts of trona $\left(\left(\mathrm{Na}_{3} \mathrm{H}\left(\mathrm{CO}_{3}\right)_{2} .2 \mathrm{H} 2 \mathrm{O}\right)\right.$ predominantly. The salts mainly occur as agglomerates clusters in which the crystals are clumped together and are formed on and around the quartz grains, using their structure as a nucleation zone.

Keywords: SEM/ Xray-EDS; Lakes; salts; Pantanal

\section{INTRODUÇÃO}

A área de estudo se localiza no Pantanal, uma extensa planície alagável, em que o sistema deposicional fluvial predomina. Especificamente na sub-região da Nhecolândia, caracterizada por apresentar cerca de 18.000 lagoas, segundo Oliveira et al. (2016). Almeida et al. (2006) sugerem que as lagoas podem ser classificadas em salinas ou baías, de acordo com seu $\mathrm{pH}$, condutividade elétrica e conteúdo salino. A lagoa de estudo é classificada como salina, devido ao alto $\mathrm{pH}$ $(10,2)$ e alta condutividade elétrica $\left(10.710 \mu \mathrm{S} . \mathrm{cm}^{-1}\right)$, indicação da alta salinidade. As amostras analisadas foram coletadas na borda da lagoa salina na Fazenda Barranco Alto. As amostras são compostas por sedimento arenoso fino e sais. A importância do estudo é contribuir para o conhecimento da origem, composição e distribuição dos sais contidos nessa lagoa específica, visando contribuir com dados para o entendimento a respeito da evolução e origem desses sais em lagoas similares na Nhecolândia. 


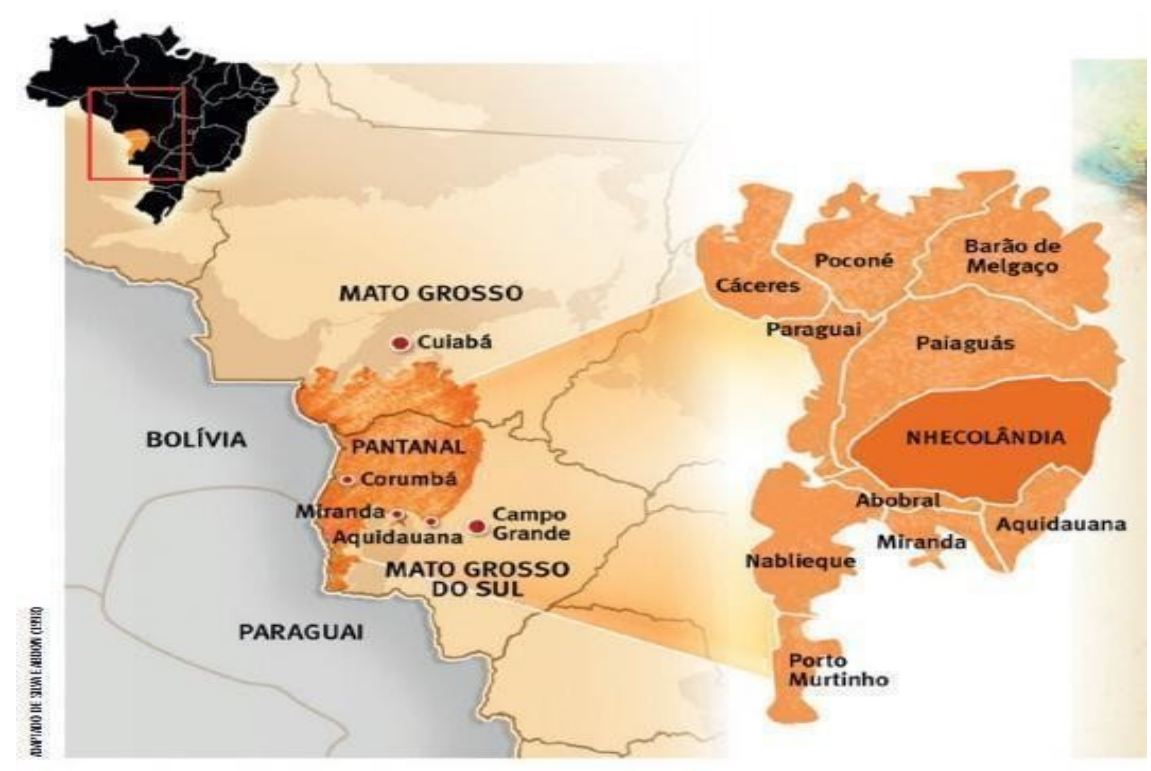

Figura 1 Localização da área de estudo, no Pantanal do Estado do Mato Grosso do Sul, na sub-região da Nhecolândia. Adaptado de Silva \& Abson (1998).

\section{MATERIAIS E MÉTODOS}

Os métodos utilizados para analisar as amostras coletadas em uma salina foram a Microscopia Eletrônica de Varredura (MEV) e a Espectrometria por energia dispersiva (EDS). Através das eletromicrografias geradas por MEV foram analisadas as características morfológicas dos sais, enquanto por meio do uso do EDS foram determinadas as composições químicas semi-qualitativa dos sais analisados.

A preparação das amostras envolveu a fixação do sedimento fino em suportes metálicos para o MEV e, o recobrimento das amostras por uma película condutora metálica de $\mathrm{Au}$, que favorece a resolução das

\section{RESULTADOS E DISCUSSÕES}

As amostras coletadas são compostas por sedimentos arenosos finos de origem fluvial e eólica, componentes do substrato da lagoa salina. Os sedimentos são formados predominantemente por grãos de quartzo bem selecionados, subarredondados a arredondados e de baixa esfericidade.

As principais características dos sedimentos foram determinadas a partir de análises de eletromicrografias. A eletromicrografia geral do sedimento (Figura 2) mostra que os grãos grossos subarredondados envoltos por aglomerados de cristais finos. O espectrograma eletromicrografias.

Dedavid et. al. (2007) indica que o MEV gera eletromicrografias a partir da incidência de elétrons na amostra, emitindo um sinal composto por: elétrons Auger, elétrons secundários, elétrons retroespalhados, raios $\mathrm{X}$ e fótons. Os sinais de interesse são compostos por elétrons secundários, elétrons retroespalhados e raios $\mathrm{X}$. Os elétrons secundários originam imagens de alta resolução (3 a $5 \mathrm{~nm}$ ). Os elétrons retroespalhados formam imagens de contraste quanto ao número atômico $(\mathrm{Z})$. Já os raios $\mathrm{X}$, captados pelo EDS acoplado ao MEV, geram espectrogramas.

de raios X (Figura 3) referente à composição química dos grãos corroídos, demonstra que são constituídos de quartzo, devido ao pico proeminente de $\mathrm{Si}$. Os grãos de quartzo apresentam marcas de corrosão, efeito da dissolução química sofrida.

A eletromicrografia (Figura 4) exibe um grão grosso subarredondado de formato irregular, intensamente corroído, devido à dissolução química capaz de alterar o formato do grão. O espectrograma de raios X (Figura 5) indica que o grão corresponde a quartzo, devido ao pico proeminente de $\mathrm{Si}$. 


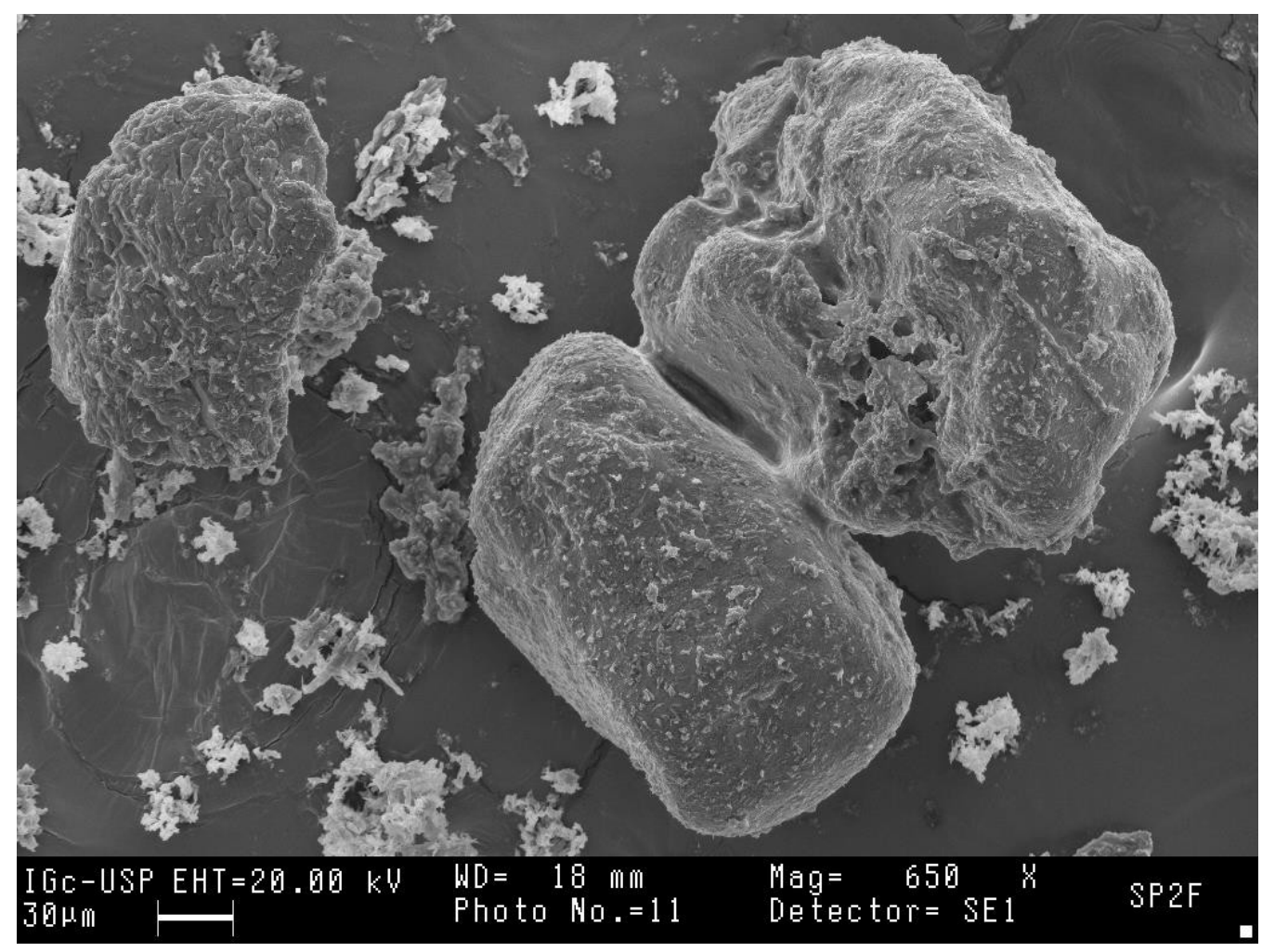

Figura 2

Eletromicrografia gerada por elétrons secundários com aumento de 650 vezes. Destaque para os grãos grossos de quartzo e os aglomerados de cristais finos no entorno com indicação de corrosão por dissolução da sílica.

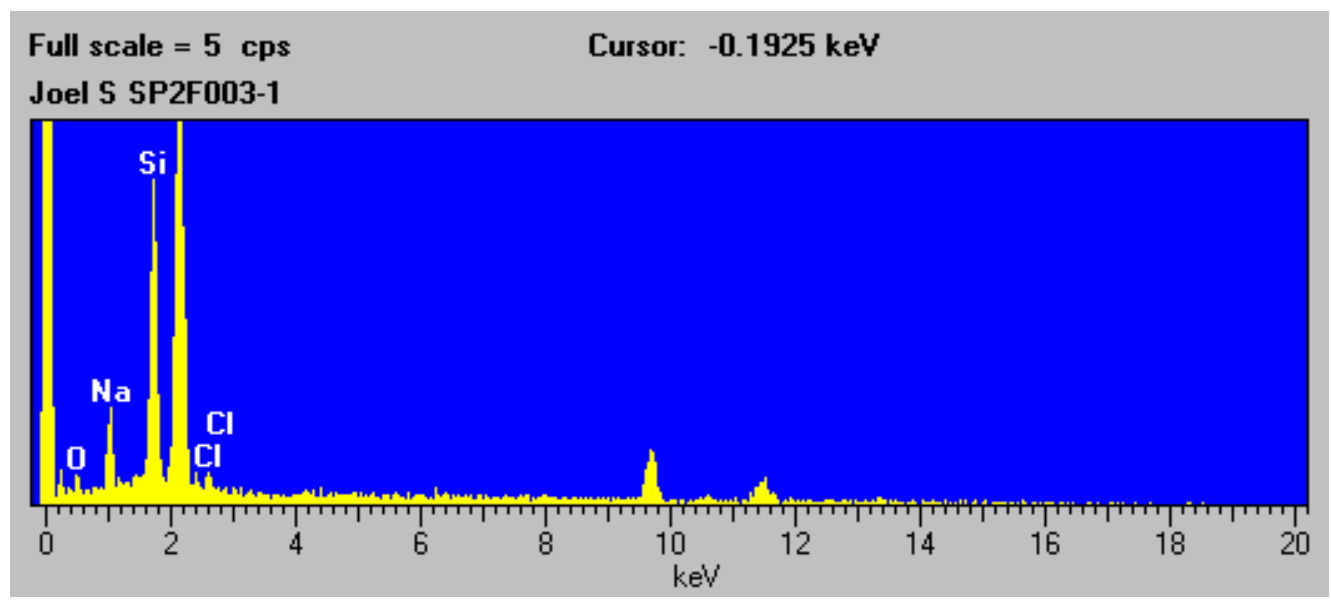

Figura 3

Espectrograma de raios $\mathrm{X}$ obtido por energia dispersiva demonstra que os grãos correspondem ao mineral quartzo. 


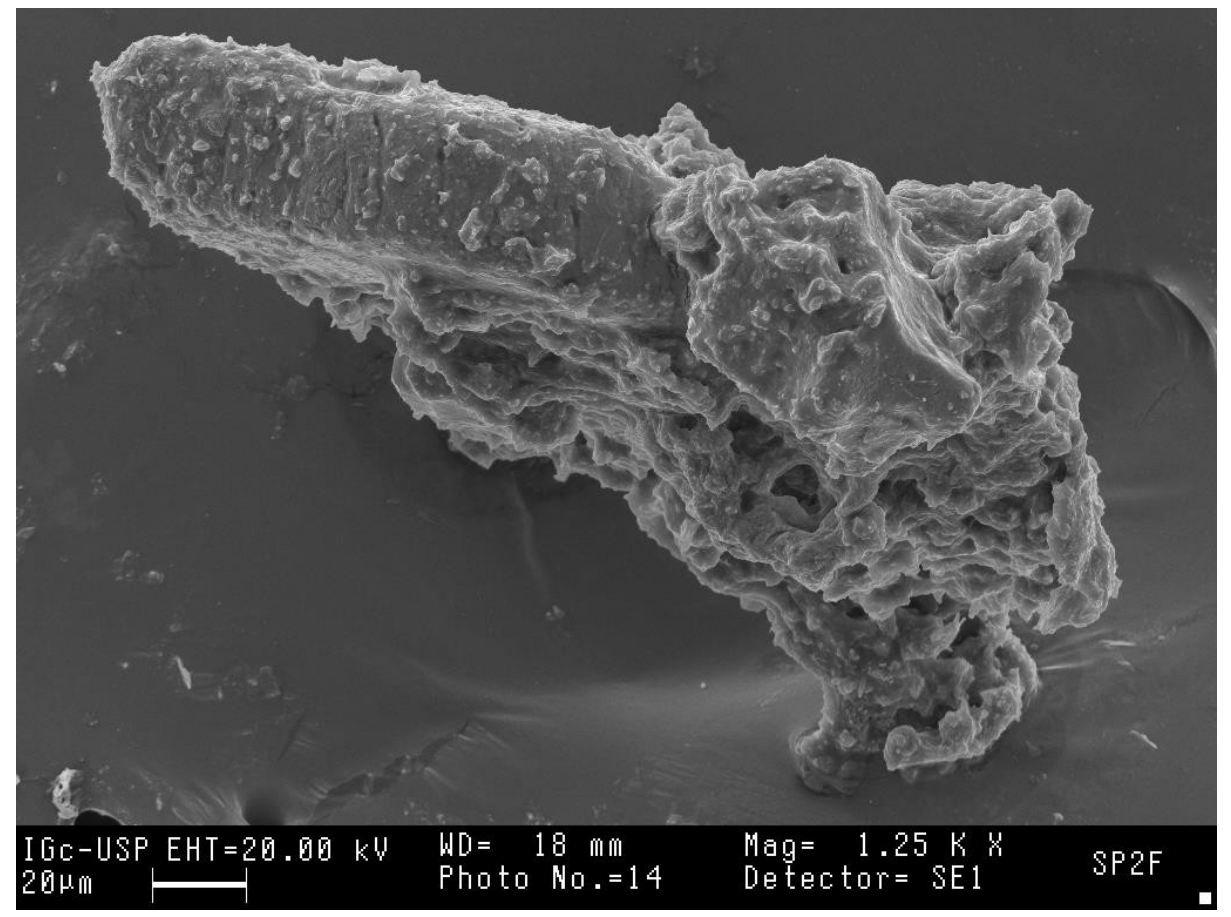

Figura 4

Eletromicrografia gerada por elétrons secundários com aumento de 1250 vezes, exibindo um grão de quartzo destacado pelas marcas de corrosão.

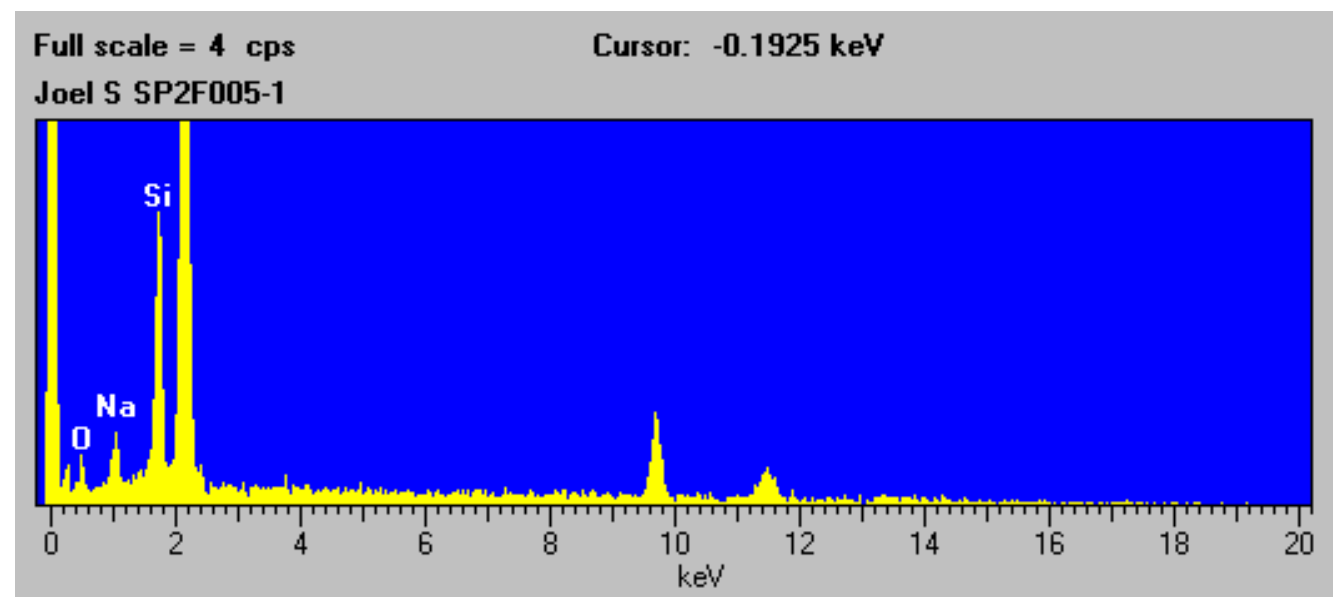

Figura 5

Espectrograma de raios $\mathrm{X}$ obtido por energia dispersiva delimita que o grão é quartzo.

As marcas de corrosão que alteram as faces e o formato dos grãos de quartzo são resultado do processo de dissolução química. A dissolução química do quartzo depende da solubilidade do íon $\mathrm{Si}^{+4}$, que varia de acordo com o $\mathrm{pH}$. A solubilidade do cátion é muito baixa em pHs ácidos e neutros, aumenta sob pHs alcalinos, superiores a 9, condição atingida durante o período climático seco na lagoa estudada. Assim, o comportamento do íon $\mathrm{Si}^{+4}$ varia durante o ano nas lagoas salinas. $\mathrm{Na}$ época de estiagem, a baixa precipitação e a elevada taxa de evaporação, contribuem para o aumento do pH (acima de 9), consequentemente ocorre a dissolução química da sílica, indicada pelas marcas de corrosão verificadas nas eletromicrografias nos grãos de quartzo. Assim, a forte dissolução verificada nos cristais grossos, grãos de quartzo, é devida à elevada alcalinidade do ambiente, condição sob a qual a sílica é solubilizada. Durante o período chuvoso, o $\mathrm{pH}$ se torna menos alcalino (menor que 9), devido à maior precipitação e consequente diluição. A precipitação de sílica 
é favorecida, preenchendo poros, auxiliando no isolamento da salina em relação ao nível freático.

Além dos grãos de quartzo, o sedimento é formado por cristais de sais, precipitados nas bordas de ressecamento no período de estiagem, época da amostragem. A morfologia e a composição química semi-qualitativa dos sais foram analisados. A eletromicrografia (Figura 6) exibe o arranjo geral não orientado dos sais. Nota-se a ocorrência de cristais de morfologia variada aglomerados entre si. As principais morfologias identificadas são cristais de hábito lamelar (seta 1), fibroso (seta 2), botrioidal (seta 3) e formato alongado (seta 4). O espectrograma de raios $X$ (Figura 7) aponta que os cristais são sais de trona $\left(\mathrm{Na}_{3} \mathrm{H}\left(\mathrm{CO}_{3}\right)_{2} \cdot 2 \mathrm{H}_{2} \mathrm{O}\right)$, bicarbonato de sódio típico de ambientes evaporíticos, indicado pelo pico proeminente de $\mathrm{C}$ e o pico significativo de $\mathrm{Na}$.

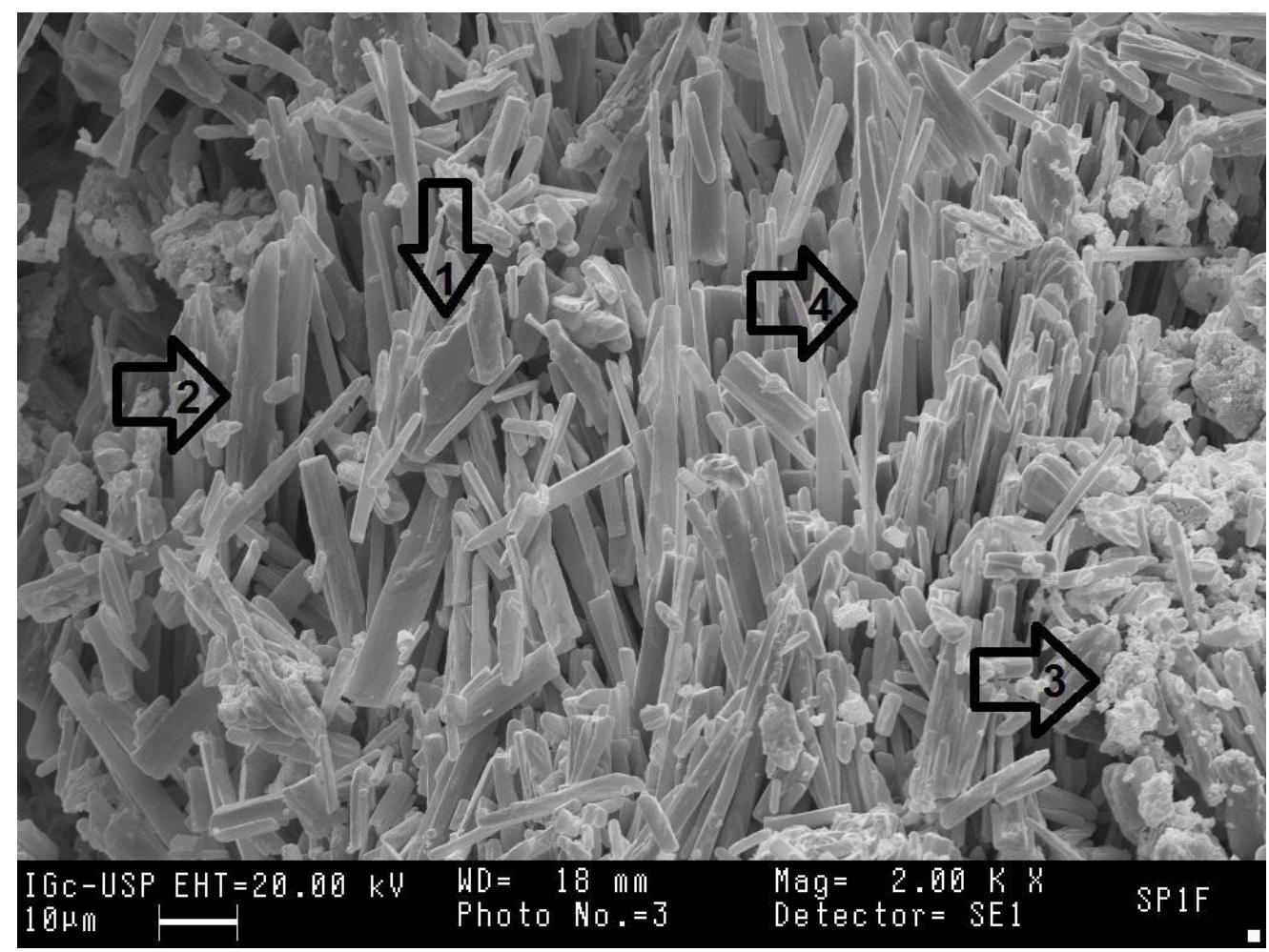

Figura 6

Eletromicrografia gerada por elétrons secundários em detalhe de aumento de 2000 vezes. Destaca as principais morfologias dos sais indicadas pelas setas.

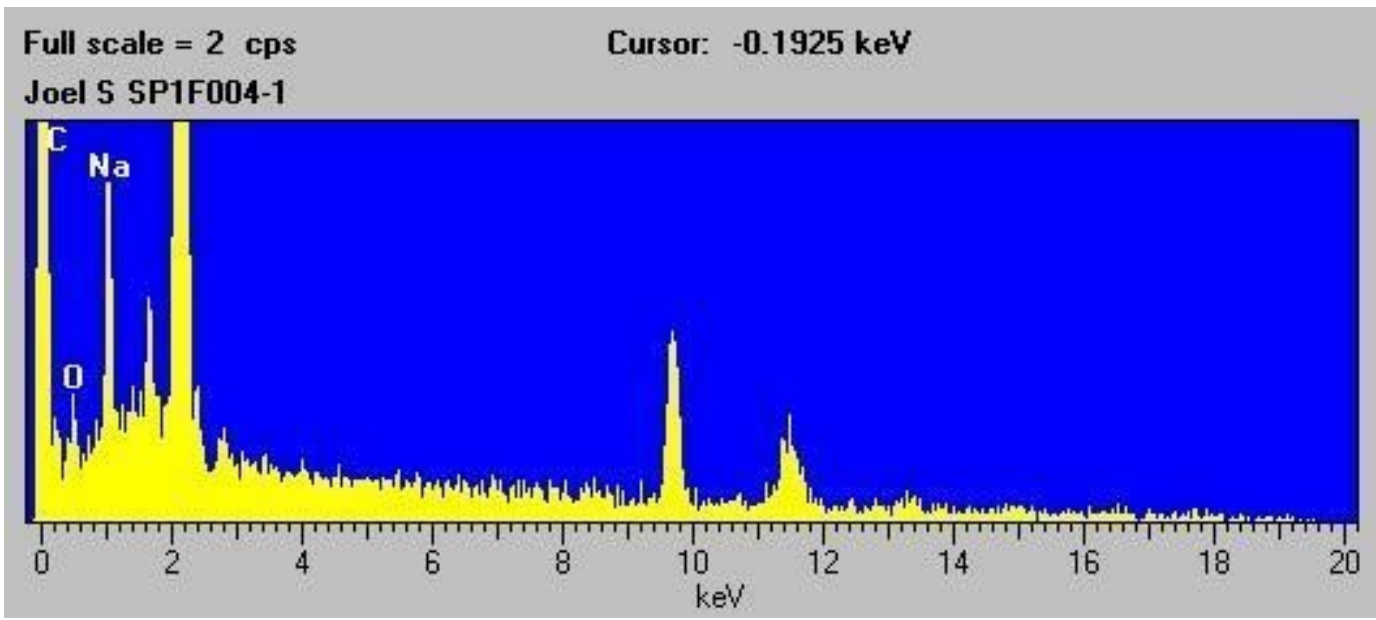

Figura 7

Espectrograma de raios $X$ obtido por energia dispersiva demonstra que os sais são cristais de trona $\left(\mathrm{Na}_{3} \mathrm{H}\left(\mathrm{CO}_{3}\right)_{2} \cdot 2 \mathrm{H}_{2} \mathrm{O}\right)$. 
A eletromicrografia (Figura 8) de detalhe destaca um cristal de hábito cúbico (seta 1), cristal fraturado envolto por um aglomerado de glomérulos de hábito botrioidal (seta 2). Associados ocorrem ainda sais de hábito fibroso (seta 3) e hábito lamelar (seta 4) não identificados com precisão.

A eletromicrografia (Figura 9) mostra cristais de sais desenvolvidos sobre e no entorno do grão de quartzo (seta 1) desenvolvidos sobre um grão de quartzo, sais de hábito botrioidal, lamelar e formato alongado. Os cristais formam uma matriz envolvendo o grão de quartzo, o arcabouço. $\mathrm{O}$ espectrograma de raios $X$ (Figura 10) comprova que o grão se trata de um quartzo, devido ao pico proeminente de Si.

A eletromicrografia (Figura 11) destaca a presença de uma estrutura côncava (seta 1) formada pela deposição dos sais de morfologia predominantemente alongada, presente em outras porções das amostras analisadas. Destaca-se ainda a presença de grãos de quartzo envoltos pela matriz de sais (seta 2).

A eletromicrografia (Figura 12) destaca uma porção côncava curvilínea (seta 1), constituída por cristais de sais de diversas morfologias. Essa feição côncava possivelmente representa molde de uma alga ou de uma macrófita, ambas comuns nesse ambiente.

A eletromicrografia (Figura 13) retrata um sítio de deposição de sais, em que os cristais originaram uma estrutura côncava em um padrão fibro-radiado (seta 1).

A eletromicrografia (Figura 14) mostra um aglomerado de sais de diversas morfologias. $\mathrm{O}$ espectrograma de raios $X$ (Figura 15) demonstra que os sais correspondem a trona $\left(\mathrm{Na}_{3} \mathrm{H}\left(\mathrm{CO}_{3}\right)_{2} .2 \mathrm{H}_{2} \mathrm{O}\right)$, devido ao pico proeminente de $\mathrm{C}$ e o pico significativo de $\mathrm{Na}$.

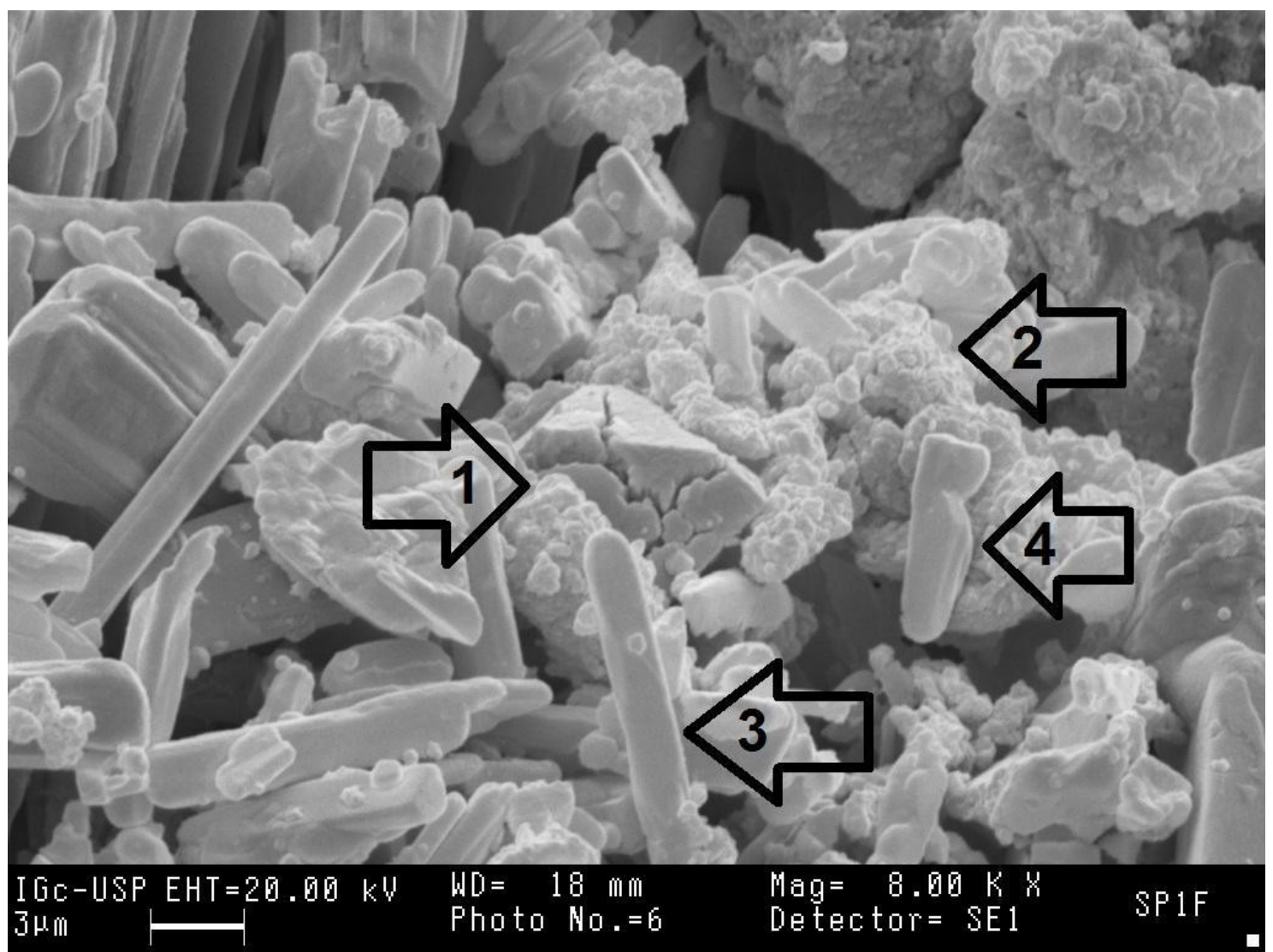

Figura 8 Eletromicrografia gerada por elétrons secundários de detalhe com aumento de 8000 vezes, que destaca o cristal de hábito cúbico. 


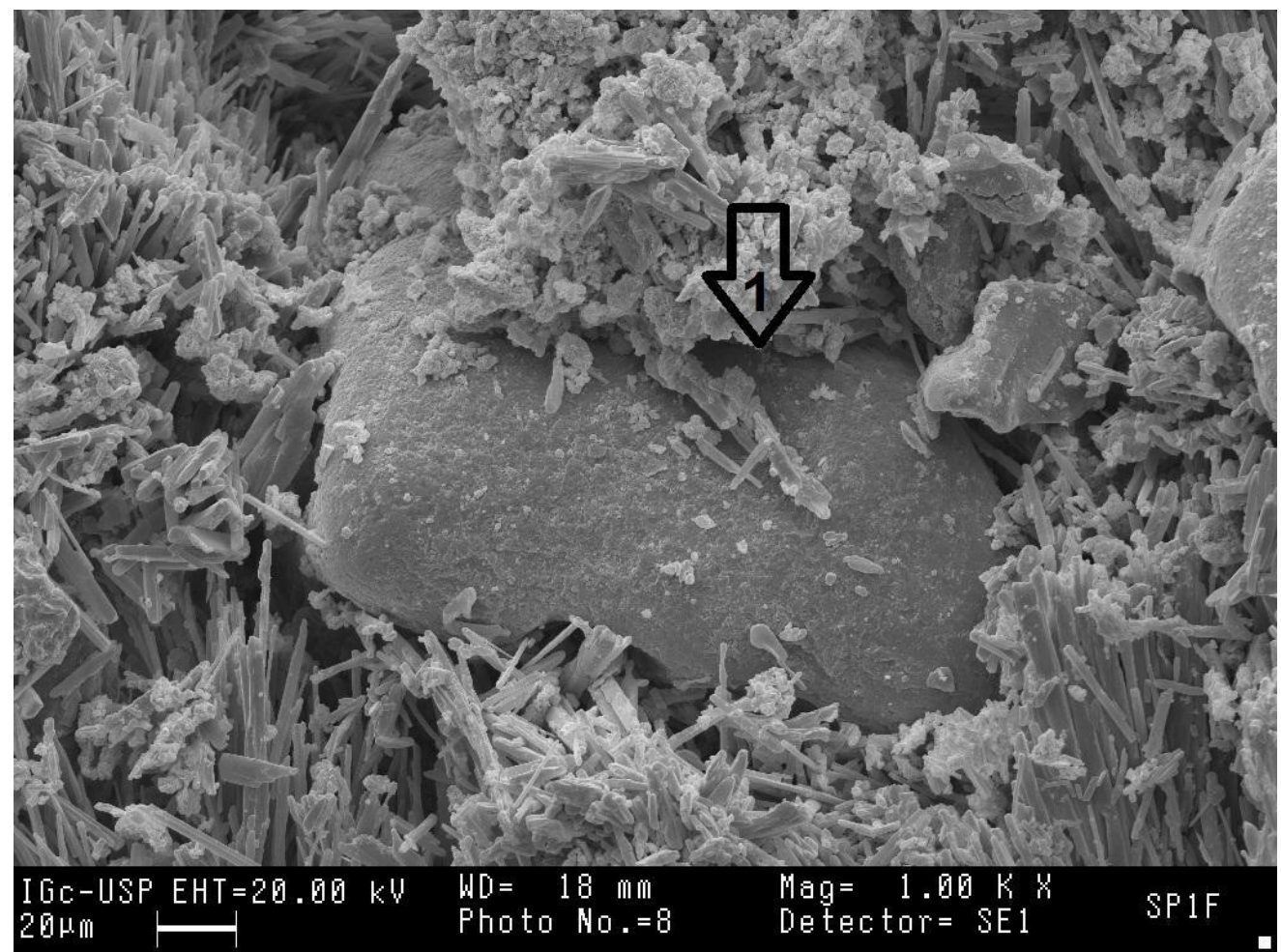

Figura 9 Eletromicrografia gerada por elétrons secundários com aumento de 1000 vezes, destaca o grão de quartzo envolto por cristais de sais onde predomina a trona.

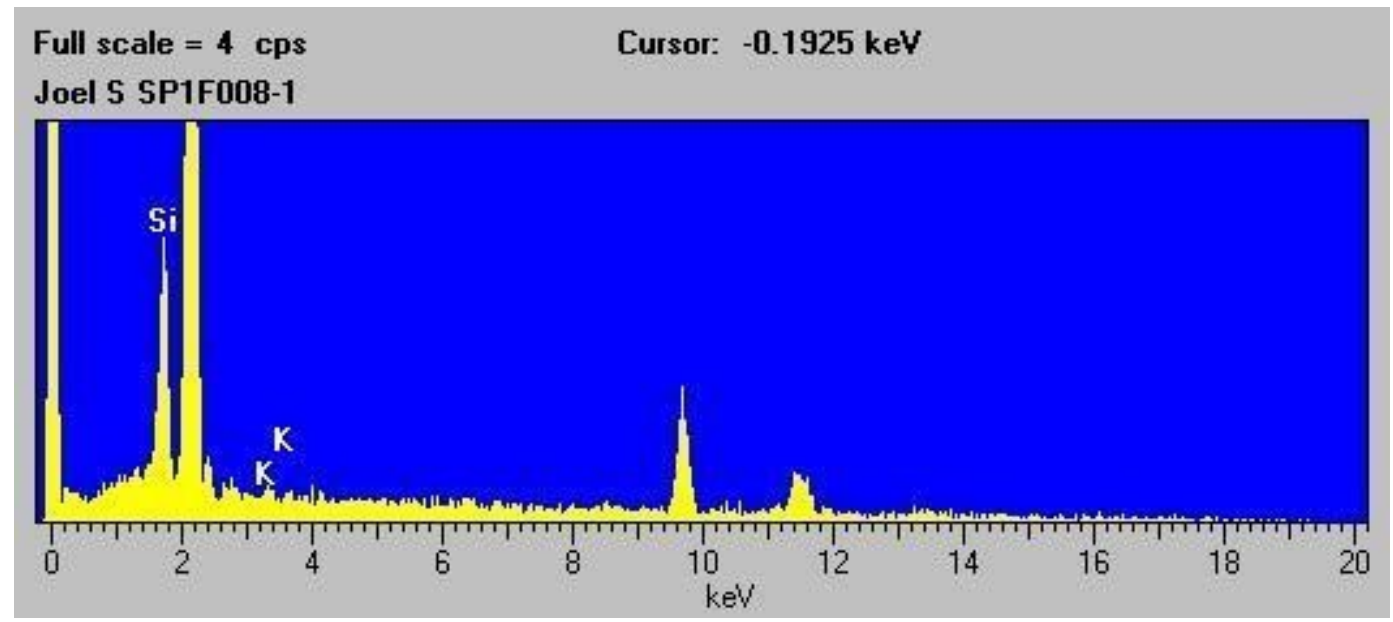

Figura 10

Espectrograma de raios $\mathrm{X}$ obtido por energia dispersiva exibe composição compatível com o mineral quartzo. 


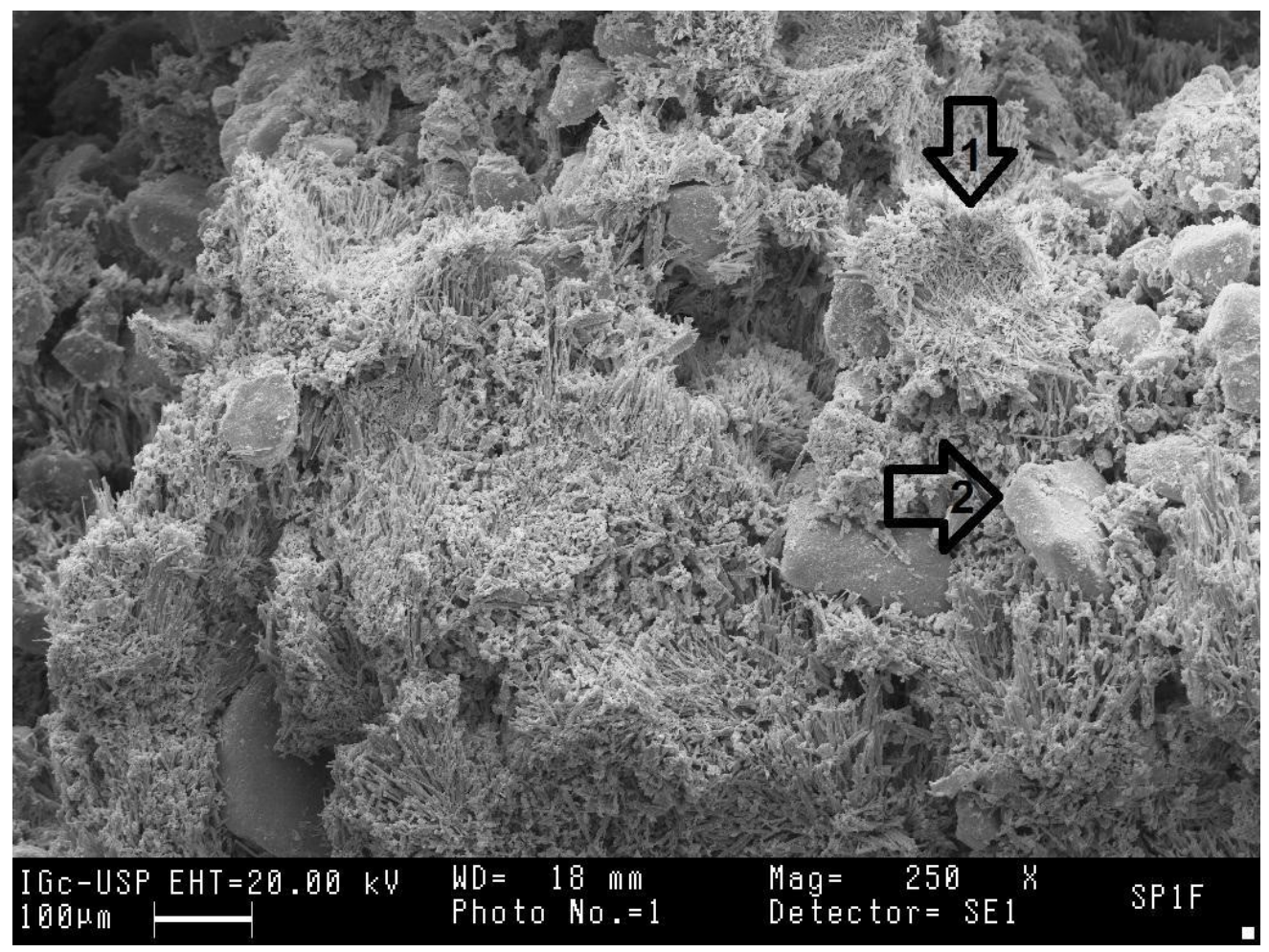

Figura 11

Eletromicrografia gerada por elétrons secundários com aumento de 250 vezes, mostra a disposição geral dos cristais de sais de diferentes composições, mas com predomínio de trona.

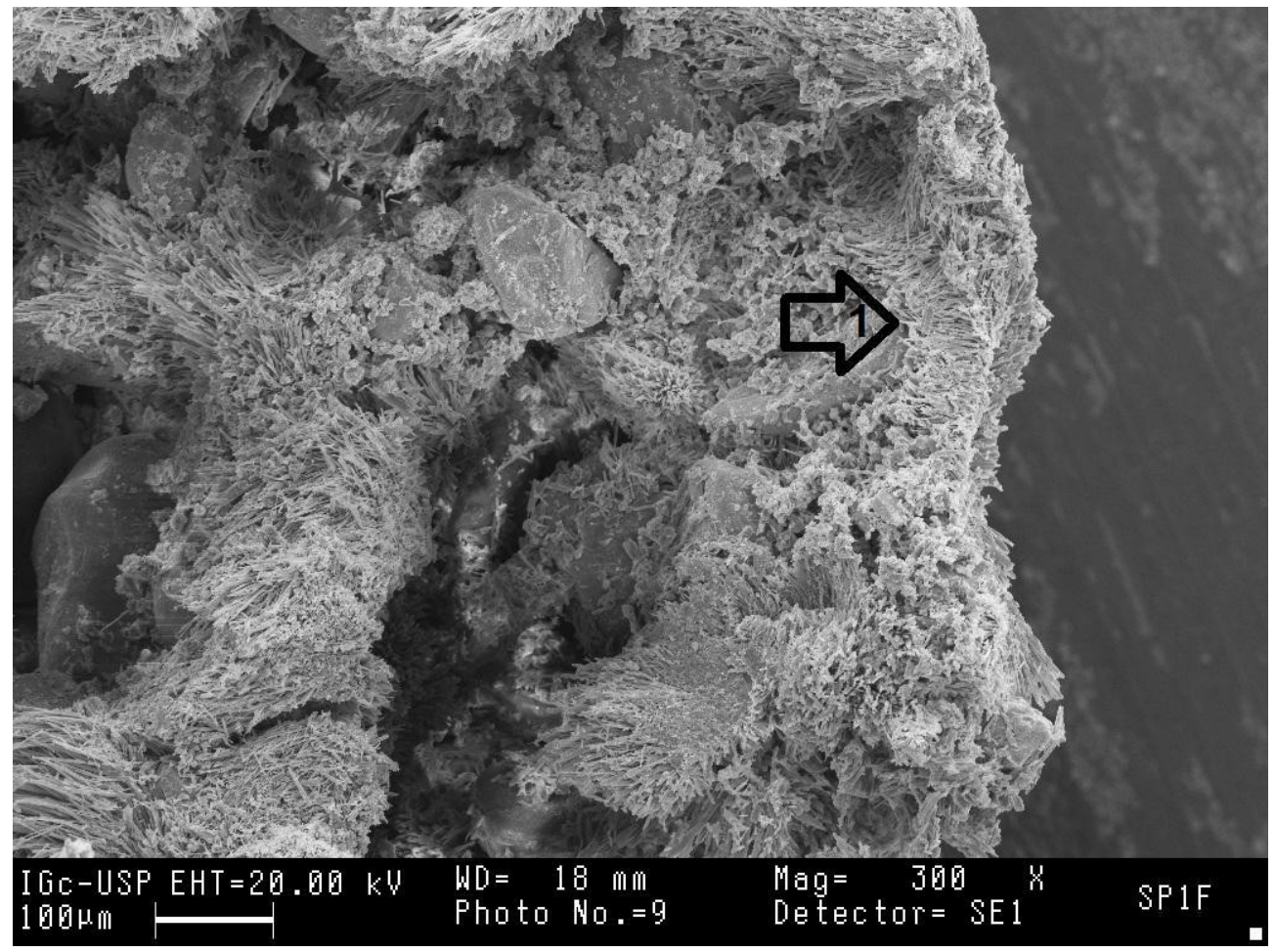

Figura 12

Eletromicrografia gerada por elétrons secundários com aumento de 300 vezes, mostrando uma estrutura cloncava presente no aglomerado de sais. 


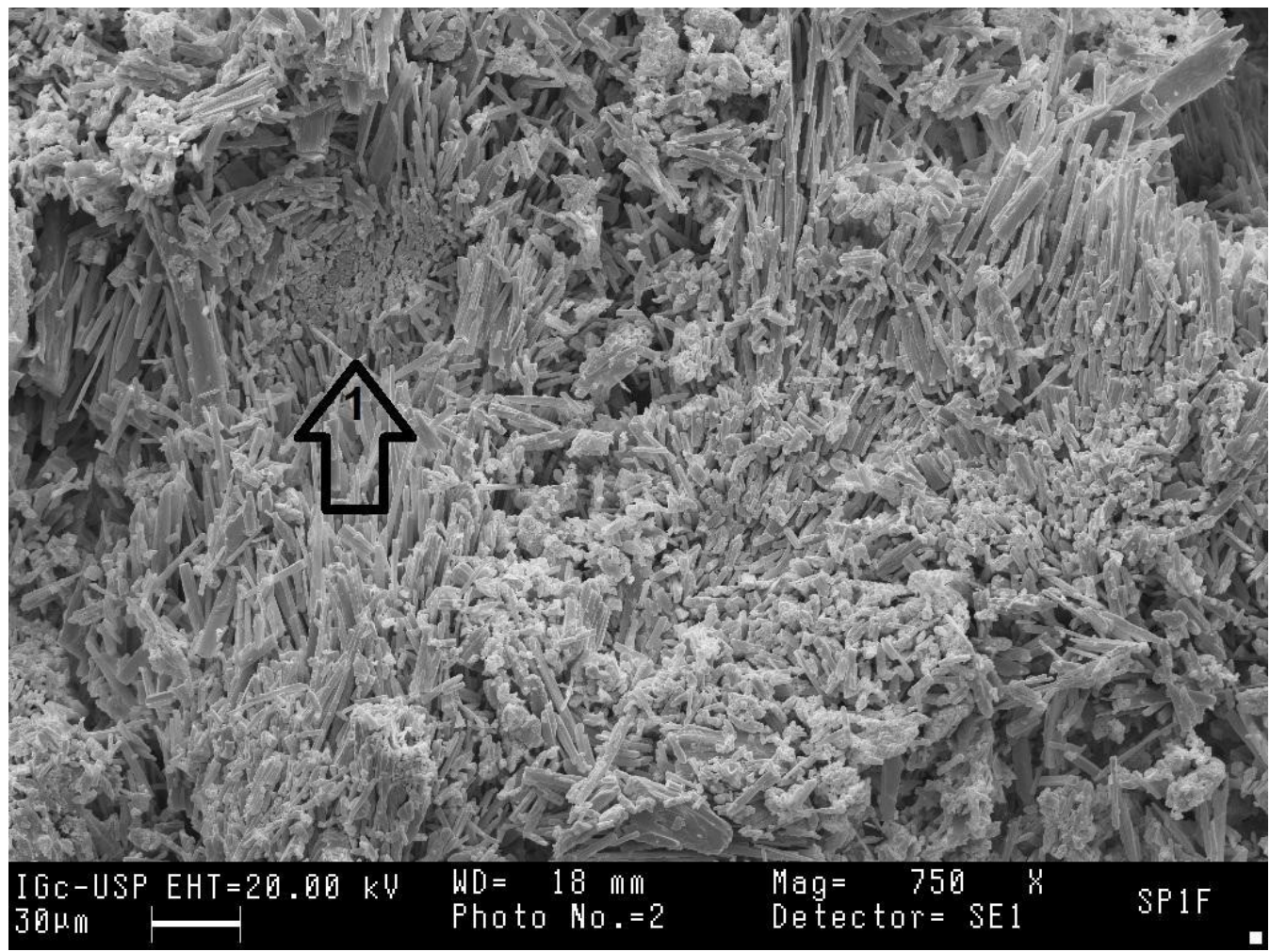

Figura 13

Eletromicrografia gerada por elétrons secundários com aumento de 750 vezes, exibindo o padrão fibro-radiado dos sais.

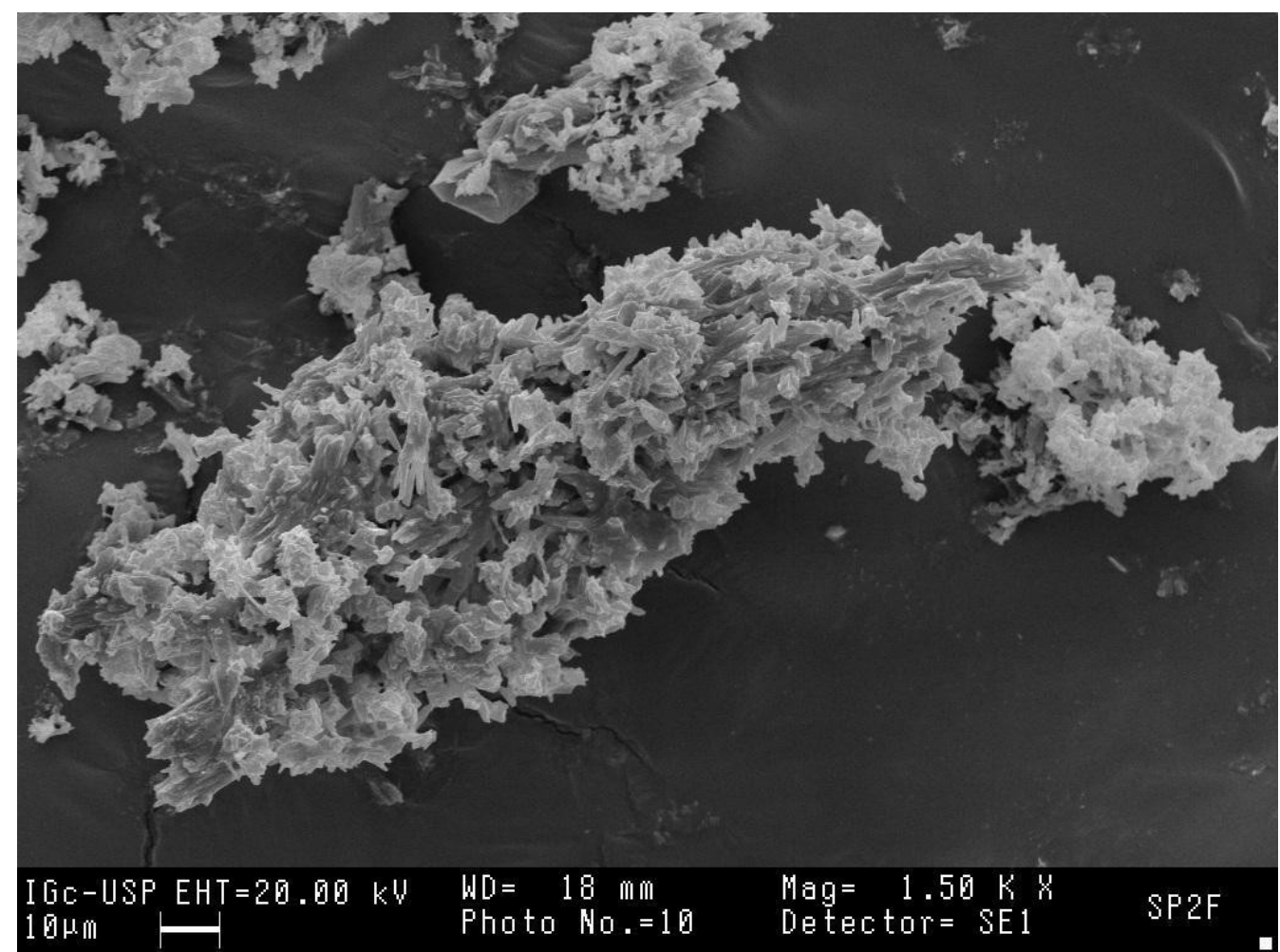

Figura 14

Eletromicrografia gerada por elétrons secundários com aumento de 1500 vezes mostra um aglomerado de sais. 


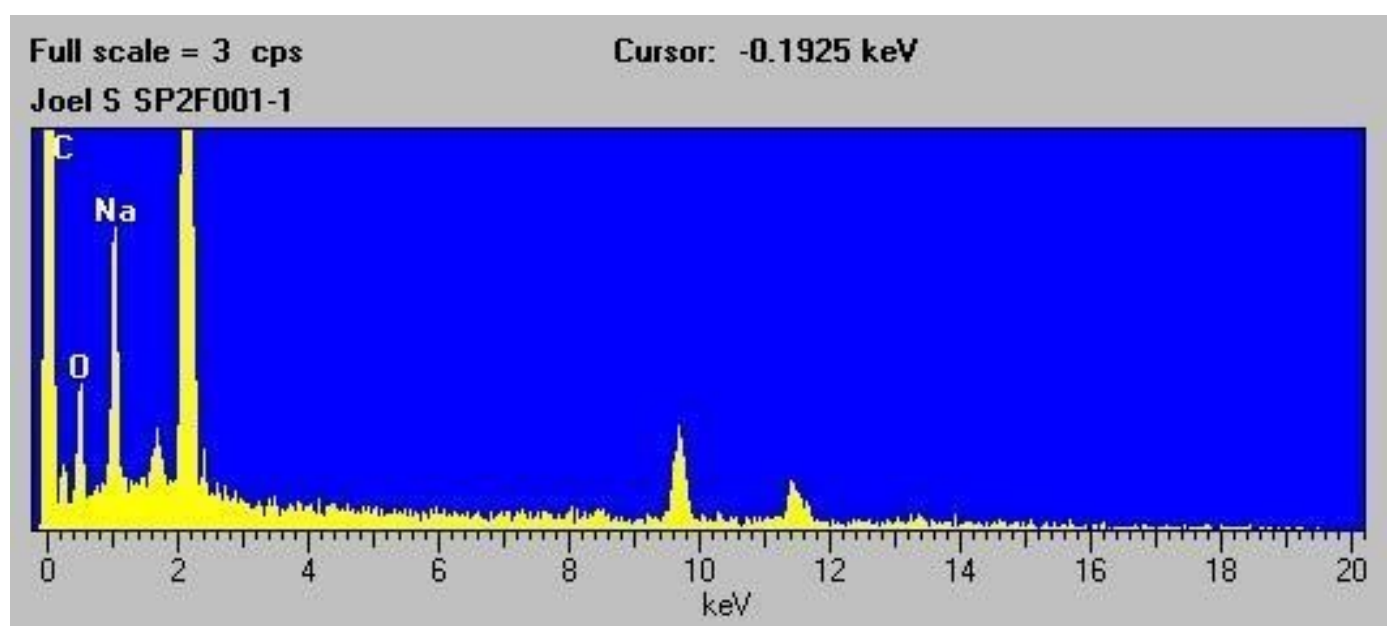

Figura 15

Espectrograma de raios $\mathrm{X}$ obtida por energia dispersiva mostra que o aglomerado de sais é formado por trona $\left(\mathrm{Na}_{3} \mathrm{H}\left(\mathrm{CO}_{3}\right)_{2} \cdot 2 \mathrm{H}_{2} \mathrm{O}\right)$.

As principais morfologias identificadas nos sais foram os hábitos lamelar, fibroso, botrioidal e formato alongado. Os cristais de hábito lamelar ocorrem associados a outros cristais ou empilhados entre si. Já os cristais de hábito colunar e formato alongado são mais frequentes, também se associam sem orientação preferencial. Enquanto os cristais de hábito botrioidal ocorrem aglutinados entre si, formando glomérulos associados a outros cristais. Os sais correspondem de acordo com as análises químicas semi-qualitativas predominante à trona $\left(\mathrm{Na}_{3} \mathrm{H}\left(\mathrm{CO}_{3}\right)_{2} .2 \mathrm{H}_{2} \mathrm{O}\right)$, indicando que uma mesma espécie de sal se precipita em diferentes morfologias. A diversidade de morfologias sugere a existência de compostos salinos não detectados de outras composições químicas.

Os sais estão dispostos sem orientação preferencial, apenas localmente há um padrão fibro- radiado presente em estruturas côncavas, que provavelmente indicam a presença de zonas de nucleação e, desenvolvem-se no entorno dos grãos de quartzo, possivelmente aproveitando a estrutura dos grãos de quartzo para sua nucleação. A estrutura côncava alongada (Figura 12) pode ser interpretada como um possível molde de algas cianofíceas, existentes nas lagoas salinas. As algas compõem parte da camada lamosa (Figura 16) rica em matéria orgânica presentes no fundo e nas margens das lagoas, local de formação dos sais. Assim os sais teriam sido formados se amoldando à forma cilíndrica da alga, gerando a feição côncava.

O ambiente da lagoa salina é favorável à formação dos sais durante o período de estiagem. A saturação dos solutos na salina está relacionada ao intenso processo de evaporação, que contribui para o aumento da salinidade e consequente precipitação química dos sais. No período de seca, o processo de dissolução química do quartzo também é favorecido, devido ao aumento de $\mathrm{pH}$. A precipitação química de sais é favorecida também pelo isolamento da salina em relação ao nível freático, que mantém a elevada salinidade e o alto $\mathrm{pH}$. A camada lamosa de baixa permeabilidade, rica em matéria orgânica e algas, é um fator da impermeabilização das salinas em relação ao nível freático. Outro fator para impermeabilização provavelmente é a precipitação de sílica secundária por entre os grãos de quartzo, agindo como cimento. A precipitação química dos sais está relacionada à impermeabilização das salinas em relação ao freático, que impede o contato com águas mais diluídas, que poderia ocasionar a diminuição da salinidade e do $\mathrm{pH}$. 


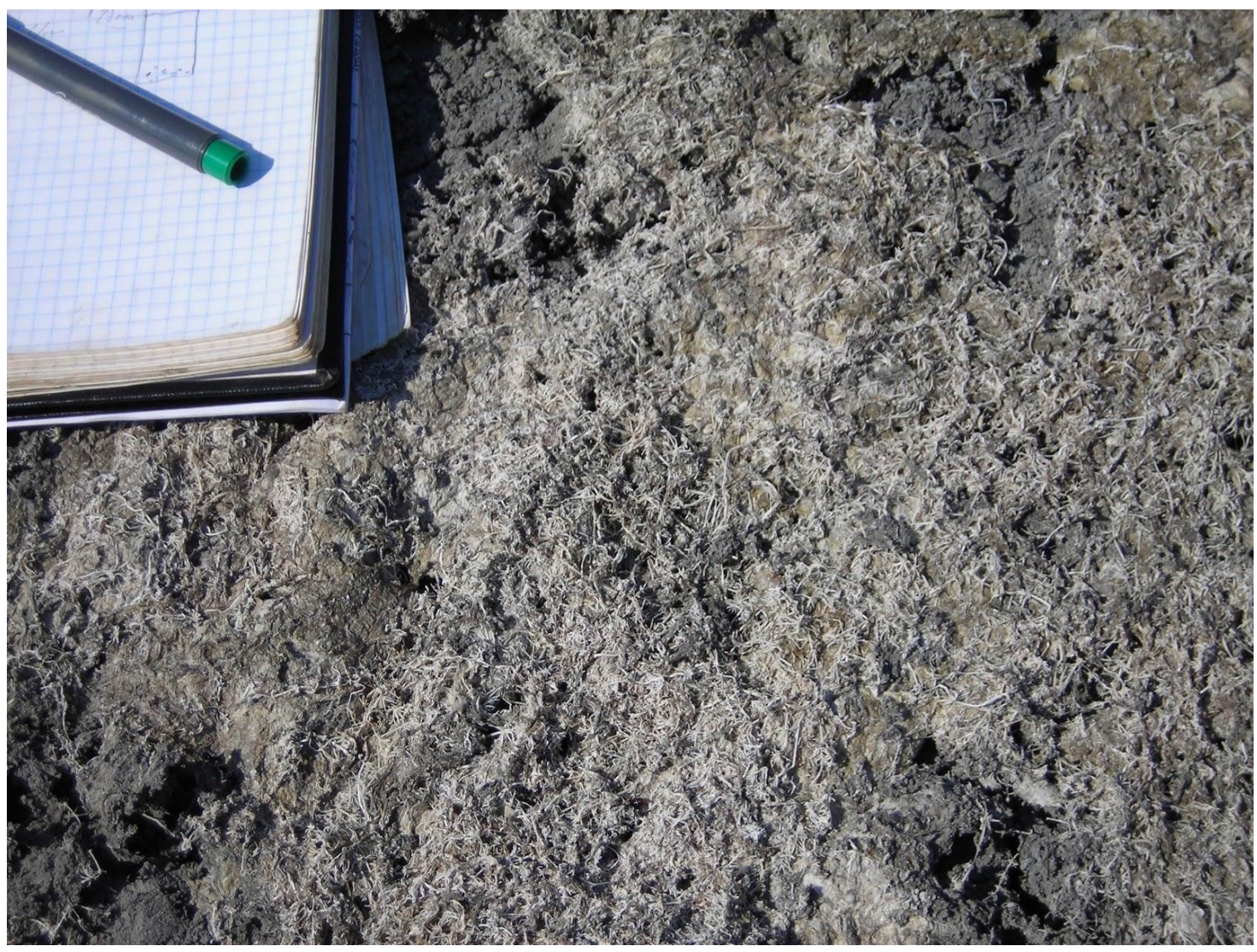

Figura 16

Camada lamosa de coloração amarronzada rica em algas de coloração clara e formato cilíndrico alongado. Um dos locais de amostragem dos sais.

\section{CONCLUSÕES}

Os sais foram caracterizados quanto a sua morfologia, química e relação com os grãos de quartzo. Dentre a variedade de morfologias existentes as mais frequentes são os hábitos lamelar, fibroso, botrioidal e o formato alongado. $\mathrm{O}$ espécime de sal predominante é a trona $\left(\mathrm{Na}_{3} \mathrm{H}\left(\mathrm{CO}_{3}\right)_{2} \cdot 2 \mathrm{H}_{2} \mathrm{O}\right)$, sal de morfologia alongada condizente com sais de formato alongado e hábitos lamelar e fibroso. Os sais se formam sobre e no entorno dos grãos de quartzo, possivelmente utilizando sua estrutura como zona de nucleação. Os grãos de quartzo, que constituem o substrato das lagoas, se caracterizam pela presença de marcas de

\section{AGRADECIMENTOS}

Aos responsáveis pela Fazenda Barranco Alto pelo apoio logístico, ao Eng. Isaac Jamil corrosão geradas por dissolução química, que indica $\mathrm{pH}$ superior a 9 .

A elevada salinidade do sistema estudado, principalmente durante o período climático seco, indica que há alta concentração de solutos, favorável à precipitação química dos sais. Portanto, os sais são formados no período seco, época de maior taxa de precipitação. Os sais estão associados às algas compondo a camada lamosa, contribuindo para impermeabilização das salinas em relação ao nível freático, consequentemente favorecendo a precipitação dos sais.
Sayeg e ao Prof. Dr. Antônio C. Paranhos Filho pelas orientações. 


\section{REFERÊNCIAS}

Almeida, T. I. R., Fernandes, E., Mendes, D., Sígolo, J. B. (2006). Distribuição espacial de diferentes classes de lagoas no Pantanal de Nhecolândia, MS: uma contribuição ao estudo de sua compartimentação e gênese. Anais $1^{\circ}$ Simpósio de geotecnologias no Pantanal, Campo Grande, Brasil, Embrapa Informática Agropecuária/INPE, 1, 155164.

Dedavid, B. A., Gomes, C. I., Machado G. (2007). Microscopia eletrônica de varredura: Aplicações e preparação de amostras em materiais poliméricos, metálicos e semicondutores ( $1^{\mathrm{a}}$ ed.). Porto Alegre: EDIPUCRS.

Oliveira, A. P. G., Mioto C. L., Ribeiro, A. A., Jaquez, R., Albrez, E. A., Sígolo, J. B., Assine, M. L., Paranhos Filho, A. C. (2016). Sensoriamento Remoto na Análise do Alinhamento das Lagoas do Pantanal da Nhecolândia, MS. Anuário do Instituto de Geociências - UFRJ. 39(3), 63-70.

Silva, J. S. V., Abson, M. M. (1998). Delimitação do Pantanal brasileiro e suas sub-regiões. Pesquisa Agropecuária Brasileira, Brasília, 33(1), 1703-1711. 